\title{
Cabazitaxel - A Treatment Option in Recurrent Platinum-resistant Ovarian Cancer
}

\author{
CHRISTINE VESTERGAARD MADSEN ${ }^{1}$, PARVIN ADIMI ${ }^{1}$, \\ ANDERS JAKOBSEN ${ }^{1,2}$ and KARINA DAHL STEFFENSEN ${ }^{1,2}$ \\ ${ }^{1}$ Department of Oncology, Vejle Hospital, University Hospital of Southern Denmark, Vejle, Denmark; \\ ${ }^{2}$ Institute of Regional Health Research, Faculty of Health Sciences, \\ University of Southern Denmark, Odense, Denmark
}

\begin{abstract}
Background/Aim: Treatment of recurrent platinumresistant ovarian cancer remains challenging due to the development of resistance to chemotherapy. Cabazitaxel is a new taxane that has demonstrated beneficial effect in prostate cancer patients resistant to docetaxel. Therefore, it could be anticipated to possibly also have an effect on chemotherapy resistant ovarian cancer. Patients and Methods: Twenty-six patients with chemotherapy-resistant epithelial ovarian cancer, fallopian tube or peritoneal cancer were treated with cabazitaxel at a dose of $25 \mathrm{mg} / \mathrm{m}^{2}$ (on day 1 of each 3-week cycle), until progression or inacceptable toxicity, between September 2015 and April 2018. The fraction of patients without progression after three months of treatment was the primary endpoint. Prophylaxis with granulocyte colonystimulating factor (G-CSF) was prescribed to all patients. Results: The median number of cabazitaxel infusions was 4 (range=1-18). In general, cabazitaxel was well-tolerated. The fraction of patients alive and without progression after 3 months of treatment was 54\% (14/26). The response rate was $46 \%$ (12/26) according to the Gynecological Cancer Intergroup (GCIG) criteria for CA125. Partial response (PR), evaluated by the Response Evaluation Criteria in Solid Tumors (RECIST), was found in 4/26 patients (15\%). By intention-totreat analysis, the median progression-free survival (PFS) was 3.9 months (95\% CI=1.9-4.4) using the combination of CA125 or RECIST (whichever came first), while the median overall survival (OS) was 8.4 months (95\% CI=5.1-11.0). Conclusion: Cabazitaxel holds promise as a drug in recurrent platinum-
\end{abstract}

This article is freely accessible online.

Correspondence to: Christine Vestergaard Madsen, Department of Oncology, Vejle Hospital, Beriderbakken 4, DK-7100 Vejle, Denmark. Tel: +45 79406030, e-mail: Christine.Vestergaard.Madsen@rsyd.dk

Key Words: Platinum-resistance, recurrent ovarian cancer, chemotherapy, cabazitaxel, phase II randomized study. resistant ovarian cancer. It demonstrated efficacy and in general, the toxicity was manageable.

Taxane-based chemotherapy plays a major role in the treatment of both platinum-sensitive and platinum-resistant ovarian cancer. Paclitaxel or docetaxel form part of the standard first-line regimen in combination with carboplatin (+/- supplementary biologically targeted agents). In most cases the combination is administrated every three weeks for a total of six cycles $(1,2)$. Another option is the dose-dense regimen with weekly paclitaxel given in combination with carboplatin every three weeks. However, data are conflicting as to whether this schedule is favorable over the standard schedule with respect to efficacy and toxicity (3-5).

Previously, patients were routinely retreated with paclitaxel and carboplatin after platinum-sensitive relapse. However, paclitaxel has now been replaced by liposomal doxorubicin at many centers, due to its less favorable toxicity profile (6-8).

In recurrent platinum-resistant ovarian cancer, paclitaxel is considered a standard option among other cytostatics (9-12). However, in these patients, the development of drug resistance constitutes a major therapeutic problem, and new treatment approaches are certainly needed. A considerable fraction of patients with chemotherapy-resistant ovarian cancer are still in good performance status and have a strong wish for further treatment $(13,14)$. Focus should therefore be on disease control, side effects, and quality of life. The novel taxane cabazitaxel has demonstrated effect in both prostate and breast cancer previously treated with taxane-based chemotherapy (15, 16). Consequently, it may be anticipated that cabazitaxel could also be effective in chemotherapy-resistant ovarian cancer, a hypothesis that motivated the present study.

Cabazitaxel is a semi-synthetic taxane derived from the 10-deacetyl Baccatin III extracted from European yew needles, and like other taxanes, it stabilizes microtubules and inhibits mitotic and interphase cellular functions. In vivo studies have indicated that cabazitaxel may exhibit antitumor 
activity in tumor models both sensitive and insensitive to chemotherapy, including docetaxel. Furthermore, it seems to be able to cross the blood-brain barrier (17).

\section{Patients and Methods}

Ethics approval and informed consent. The presented results originate from the protocol Cabazitaxel vs. Tocotrienol in patients with recurrent ovarian cancer after failure of standard therapy - A phase II randomized open-label study. ClinicalTrials.gov Identifier: NCT02560337. The protocol was approved by the Regional Committee on Health Research Ethics for Southern Denmark and the Danish Medicines Agency. Written informed consent was provided by all patients and the Helsinki II Declaration was strictly observed.

Patient selection. Twenty-six patients with verified progression of epithelial, primary fallopian or primary peritoneal cancer were enrolled in this study. All participants had either platinum-resistant disease with at least two previous cytostatic regimens or platinumrefractory disease, defined as progression on platinum-based therapy or within 4 weeks of last platinum dose. Patients with a history of severe hypersensitivity reaction ( $\geq$ grade 3 ) to paclitaxel or neuropathy grade $\geq 2$ were excluded. All inclusion/exclusion criteria are available at ClinicalTrials.gov.

Treatment regimen. Cabazitaxel $\left(25 \mathrm{mg} / \mathrm{m}^{2}\right.$ on day 1 of each 3 -week cycle), was given until progression or inacceptable toxicity during the period from September 2015 to August 2018. Primary prophylaxis with lipegfilgrastim, a recombinant granulocyte colony-stimulating factor (G-CSF), was prescribed to all patients (6 mg on day two of each cycle).

Patient evaluation. A computed tomography scan was performed at baseline and every three cycles; CA125 was measured prior to each cycle. If patients were evaluable by both Response Evaluation Criteria in Solid Tumors (RECIST1.1) and by GCIG modified criteria for CA125 response, the date of progression was the date of the earlier of the two events. If a patient was evaluable by both modalities and presented a discordant response, a clear algorithm was used as described by Rustin et al. (18). In cases where a patient presented stable disease by RECIST and clear clinical benefit from the treatment, but also progression according to CA125, treatment continuation was allowed at the discretion of the treating physician.

Toxicities were reported and graded using the National Cancer Institute's Common Toxicity Criteria (NCI-CTC) version 4.0, year 2010 .

Global quality of life was assessed before start of treatment, at every response evaluation, as well as at the end of treatment, according to the questions on global health status $(\mathrm{C} 29+\mathrm{C} 30)$ included in EORTC QLQ-C30 version 3.0. (19). The recorded answers were transformed into dimensions ranged 0-100 according to the EORTC scoring instructions (20).

Initially, the study included two arms; one with cabazitaxel and the other with tocotrienol. At progression or unacceptable toxicity of either of the treatments, cross-over to the other arm was allowed, although the study was not designed to compare the two treatment arms. Tocotrienol failed to reach its primary endpoint and the arm was closed at the time of the interim analysis. Further data on tocotrienol are not described in this paper.
Table I. Patient characteristics $(N=26)$.

\begin{tabular}{lc}
\hline Characteristics & $\mathrm{N}(\%)$ \\
\hline Age at diagnosis*, years & $58(30-75)$ \\
FIGO stage & \\
I & $2(8)$ \\
II & $0(0)$ \\
III & $15(58)$ \\
IV & $9(34)$ \\
Histopathological subtype & \\
Serous** & $22(85)$ \\
Endometrioid & $1(4)$ \\
Serous + endometrioid (mixed) & $1(4)$ \\
Serous + clear cell (mixed) & $1(4)$ \\
Carcinosarcoma & $1(4)$ \\
Number of prior chemotherapy regimens* & $3(2-8)$ \\
Cabazitaxel infusions & \\
Median & 4.0 \\
Mean & 6.1 \\
Range & $1-18$ \\
$\leq 2$ cycles & $6(23)$ \\
$\geq 9$ cycles & $7(27)$ \\
Performance status at start of cabazitaxel treatment & \\
0 & $13(50)$ \\
1 & $12(46)$ \\
2 & $1(4)$ \\
Body mass index* & $24.1(18.5-35.6)$ \\
\hline
\end{tabular}

*Data presented as median (range). **including primary peritoneal and fallopian tube cancer.

Statistical analysis. The study was a phase II trial conducted according to Simon's two-stage minimax design. The fraction of patients without progression after 3 months of treatment (primary endpoint) was anticipated to be $20 \%$. The target was to increase this fraction to $50 \%$. With a significance level of $5 \%$ and a power of $80 \%$ the first step would enroll nine patients. If more than two patients were progression-free after 3 months, the study would continue to the second step for a total of 17 patients. If more than 6 were without progression at 3 months, the study would be worthy of further investigation. Secondary outcome measures were response rate (RR), progression-free survival (PFS), overall survival (OS), toxicity, and quality of life (QoL) during treatment.

The date of progression was reported for the combination of RECIST and CA125, whichever came first, as previously explained. PFS was calculated from the date of the first cycle of cabazitaxel treatment until progression or death of any cause. OS was calculated as the interval from the date of the first cycle of cabazitaxel treatment until death of any cause. Both PFS and OS were calculated and reported as median survival by the Kaplan-Meier method, illustrated by survival plots, and the log-rank test was used for comparing survival between two groups. The Mann-Whitney $U$ test was used for comparing the medians between the groups. A $p$ value $\leq 0.05$ was considered statistically significant. Number Cruncher Statistical System (NCSS version 11, Kaysville, UT, USA) software package was used for the statistical analyses. 
Table II. Response to treatment according to Response Evaluation Criteria in Solid Tumors (RECIST), Gynecological Cancer Intergroup (GCIG) criteria for CA125, and combined RECIST and CA125 criteria.

\begin{tabular}{|c|c|c|c|c|c|c|}
\hline & \multicolumn{6}{|c|}{ CA-125 response } \\
\hline & Response & SD & PD & NE by CA-125 & NE only 1 cycle & Total RECIST \\
\hline \multicolumn{7}{|l|}{ RECIST } \\
\hline PR & 4 & & & & & 4 \\
\hline $\mathrm{SD}$ & 5 & 3 & 1 & 1 & & 10 \\
\hline $\mathrm{PD}$ & 2 & 3 & 1 & 1 & & 7 \\
\hline NE by RECIST & 1 & 1 & & & & 2 \\
\hline NE only 1 cycle & & & & & 3 & 3 \\
\hline Total CA125 & 12 & 7 & 2 & 2 & 3 & 26 \\
\hline
\end{tabular}

PR, Partial response; SD, stable disease; PD, progressive disease; NE, non evaluable.

\section{Results}

Patient characteristics. Twenty-six patients received treatment with cabazitaxel. As it appears from Table I, serous adenocarcinoma was the most frequent histological subtype $(85 \%)$.

At the time of referral for cabazitaxel treatment, patients had received a median of 3 previous chemotherapy regimens (range=2-8). All patients were platinum-resistant. Twenty-five patients $(96 \%)$ had previously received taxane-based chemotherapy, while 6 (23\%) had been exposed to taxanebased chemotherapy at least in 2 different treatment regimens. Most of the patients were still in good performance status according to ECOG scale of performance status (PS 0 or $1=96 \%$ ) and with a median body mass index (BMI) of 24.1 at baseline, which is classified as normal weight.

The median number of cabazitaxel infusions was 4 (range $=1-18)$. Seven patients $(27 \%)$ received at least 6 months of treatment ( 9 cycles). At baseline, 2 patients $(8 \%)$ were not evaluable by CA125. Another two patients $(8 \%)$ with initially unmeasurable disease had only non-target lesions. The median of follow-up duration (from start of treatment until death) was 8.6 months (range=0.8-30.2).

Efficacy. In relation to response evaluation, 3 of the patients only received one cycle of cabazitaxel. Consequently, they were considered non-responders in the intention-to-treat analysis.

The fraction of patients being alive and without progression after 3 months of treatment was 54\% (14/26) according to both RECIST and GCIG criteria for CA125. A response rate of $46 \%(12 / 26)$ was found according to the GCIG CA125 criteria. Partial response (PR) evaluated by RECIST was found in $4 / 26$ patients $(15 \%)$. The response was confirmed by another scan in $3 / 26$ patients $(11.5 \%)$. Ten patients $(38 \%)$ had stable disease (SD) by RECIST in an intention-to-treat analysis. The number of patients with
Table III. Grade 3 and 4 toxicities reported per patient during treatment $(N=26)$.

\begin{tabular}{lll}
\hline & Grade 3 & Grade 4 \\
\hline Hypersensitivity & $0(0 \%)$ & $0(0 \%)$ \\
Infection & $3(12 \%)$ & $0(0 \%)$ \\
Fever without neutropenia & $3(12 \%)$ & $0(0 \%)$ \\
Febrile neutropenia & $4(15 \%)$ & $0(0 \%)$ \\
Bleeding & $0(0 \%)$ & $1(4 \%)$ \\
Nausea & $2(8 \%)$ & $0(0 \%)$ \\
Vomiting & $3(12 \%)$ & $0(0 \%)$ \\
Constipation & $2(8 \%)$ & $0(0 \%)$ \\
Diarrhea & $1(4 \%)$ & $0(0 \%)$ \\
Anorexia & $0(0 \%)$ & $0(0 \%)$ \\
Fatigue & $1(4 \%)$ & $0(0 \%)$ \\
Alopecia & $0(0 \%)$ & $0(0 \%)$ \\
Skin toxicity/rash & $0(0 \%)$ & $0(0 \%)$ \\
Nail toxicity & $0(0 \%)$ & $0(0 \%)$ \\
Neuropathy-motor & $0(0 \%)$ & $0(0 \%)$ \\
Neuropathy-sensory & $0(0 \%)$ & $0(0 \%)$ \\
Edema & $0(0 \%)$ & $0(0 \%)$ \\
Pain & $3(12 \%)$ & $0(0 \%)$ \\
Stomatitis & $1(4 \%)$ & $0(0 \%)$ \\
Heart symptoms, specify & $0(0 \%)$ & $0(0 \%)$ \\
Ileus & $2(8 \%)$ & $0(0 \%)$ \\
Dyspnea & $1(4 \%)$ & $0(0 \%)$ \\
Pulmonary embolism & $1(4 \%)$ & $0(0 \%)$ \\
\hline
\end{tabular}

response by RECIST and CA125 criteria, individually and combined, are demonstrated in Table II.

In the intention-to-treat analysis, the median PFS was 3.9 months (95\% CI=1.9-4.4) using the combination of CA125 or RECIST (whichever came first), while the median OS was 8.4 months (95\% CI=5.1-11.0) (Figures 1 and 2).

Toxicity. Seven of the patients $(27 \%)$ reported grade 1 neuropathy before start of cabazitaxel, the number of which increased to $10(38 \%)$ during treatment. No grade 2-3 


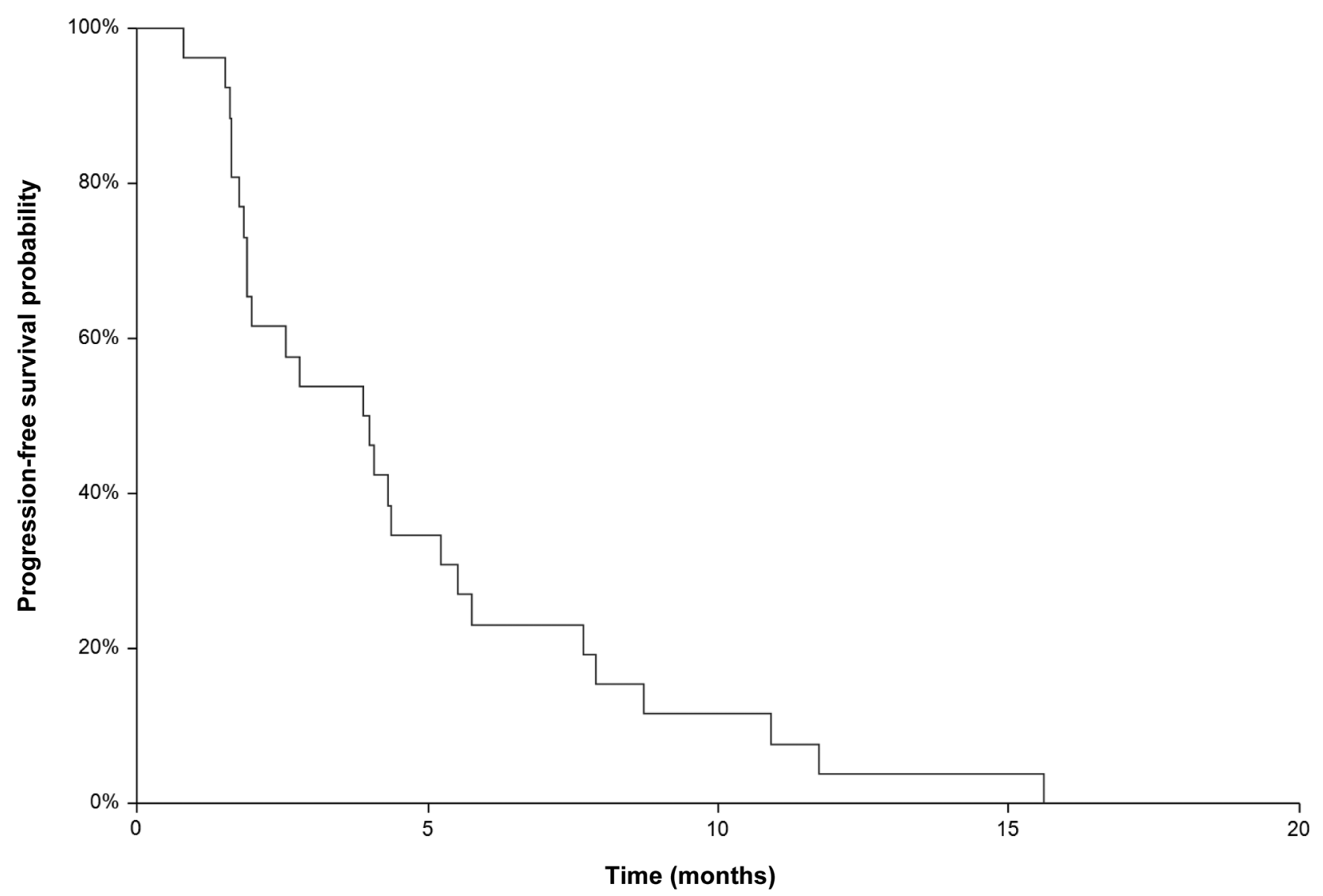

Figure 1. Progression free survival curve in 26 patients receiving cabazitaxel.

neuropathies were observed after cabazitaxel treatment. Four patients (15\%) experienced febrile neutropenia despite prophylactic G-CSF. Overall, the treatment was well-tolerated and the types of observed and reported side effects were generally consistent with the described toxicity in the summary of product characteristics for cabazitaxel. Grade 3 and 4 toxicities reported per patient during treatment are illustrated in Table III.

Quality of life evaluation. Twenty-two (85\%) patients returned the baseline questionnaire and 17 (68\%) completed both the baseline and at least one more questionnaire. Of these, $88 \%$ ended treatment due to progression and $12 \%$ due to side effects or reduced quality of life. In this group, the median number of cabazitaxel infusions was 6 (range $=2-18)$.

As shown in Figure 3, there was a clear decline in global health status/QoL from baseline to end of treatment $(p=0.006)$, and from first evaluation to end of treatment $(p=0.01)$. From baseline to first evaluation the decline was not significant. In Figure 3, only data from patients with baseline and a least one more evaluation $(n=17)$ are included.

\section{Discussion}

To the best of our knowledge, the present study is the first clinical phase II trial investigating cabazitaxel in recurrent platinum-resistant ovarian cancer patients. It was shown that more than $50 \%$ of the enrolled patients were without progression after three months of treatment, thus indicating that cabazitaxel has effect on platinum- and taxane- resistant ovarian cancer and could be considered a treatment option in this patient category.

Cabazitaxel has been investigated in a few clinical trials with different tumor types. Specifically, the phase III TROPIC trial on metastatic castration-resistant prostate cancer showed significant improvement of both PFS and OS after treatment with cabazitaxel, compared to mitoxantrone (15). Subsequently, cabazitaxel was approved for the treatment of hormonerefractory metastatic prostate cancer patients previously treated with docetaxel. Also, several phase II studies indicated that cabazitaxel has anti-tumor effect in taxane-resistant metastatic breast cancer patients (16), non-small cell lung cancer patients progressing after docetaxel-based chemotherapy (21), as well as in patients with advanced or metastatic adenocarcinoma of the esophagogastric junction and stomach (22). 


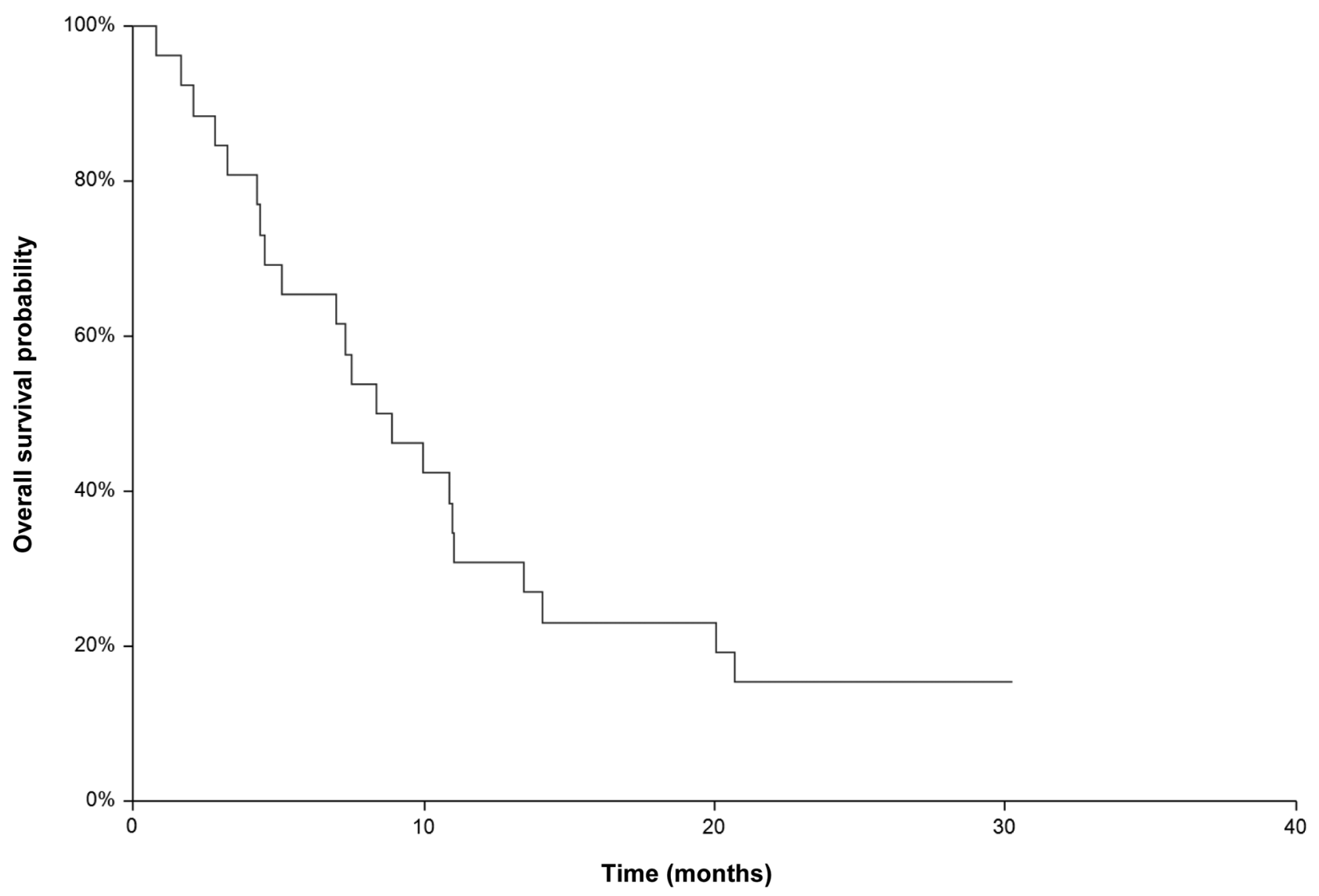

Figure 2. Overall survival curve in 26 patients receiving cabazitaxel.

The PFS of 3.9 months found in our study seems to be comparable with data in other studies investigating chemotherapy regimens in platinum-resistant ovarian cancer patients with a poor prognosis. In the standard chemotherapy arms of the Aurelia trial, the PFS was 3.9 months for paclitaxel, 3.5 for pegylated liposomal doxorubicin, and 2.1 months for topotecan. However, the OS of 8.4 months in our study was shorter than the findings in the Aurelia study with an OS of 13.2-14.1 months. An explanation of this discrepancy may be the fact that our patients were more heavily pretreated (median of 3 regimens) compared to the Aurelia study, in which a maximum of two previous chemotherapy regimens was allowed $(23,24)$.

As described in the summary of product characteristics for cabazitaxel (25), one of the very commonly reported adverse reactions is neutropenia. In order to reduce the risk of complications such as febrile neutropenia, we added prophylactic G-CSF in our study. Despite this, four patients (15\%) experienced febrile neutropenia and precautions in this respect should be taken, especially in heavily pretreated patients.

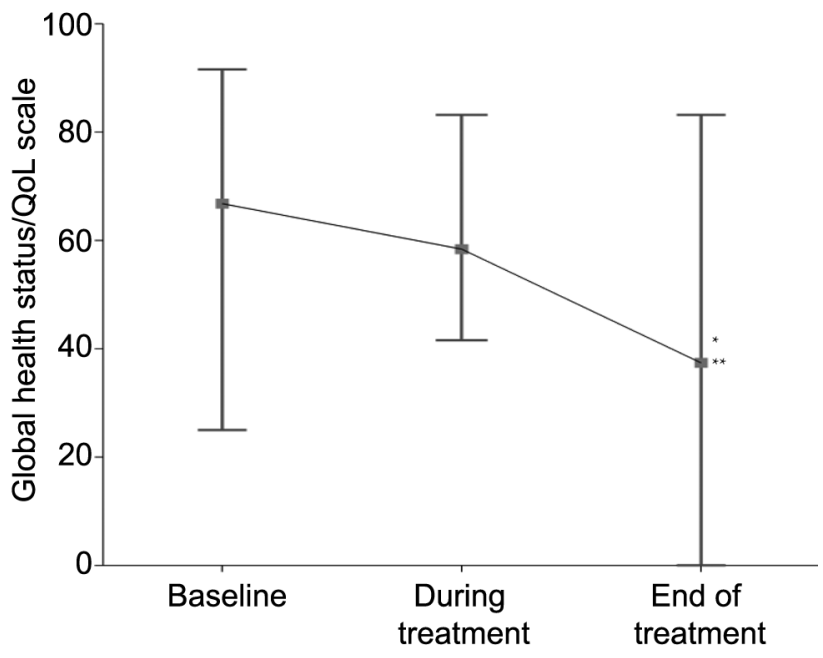

Figure 3. Global quality of life during treatment. Medians, maximum and minimum data are shown. $* * p=0.006$ for baseline vs. end of treatment; $* p=0.01$ for first evaluation vs. end of treatment. 
Chemotherapy-induced peripheral neuropathy is a commonly reported late effect in ovarian cancer patients, and has been found to occur even up to 12 years after diagnosis (26). It is known to have a negative impact on daily functioning and overall quality of life (26). The risk of taxane-induced peripheral neuropathy increases with cumulative dose received (27). Aggravation of existing peripheral neuropathy was not frequently $(11 \%)$ reported in our study and generally seems to occur less often with cabazitaxel than with docetaxel and paclitaxel (28). Therefore, cabazitaxel may be considered an alternative in the re-treatment with taxanes in patients with platinumresistant disease. However, validation of our results is needed before suggesting cabazitaxel as a treatment option among the other standard regimens in this patient category (paclitaxel, topotecan, pegylated liposomal doxorubicin, and gemcitabine).

The small sample size is one of the limitations of our study. Furthermore, it is a single center study and a nonrandomized phase II trial. In addition, the fact that not all data on QoL were available at baseline and during treatment reduces the value of this analysis. Results from this trial calls for validation. In future studies, it would be interesting to investigate the effect and toxic profile of cabazitaxel in combination with carboplatin in platinum-sensitive relapse when pegylated liposomal doxorubicin and carboplatin is contraindicated.

\section{Conclusion}

Cabazitaxel showed efficacy and safety in patients with recurrent platinum-resistant ovarian cancer, and the findings indicate that cabazitaxel is interesting for further investigation in prospective ovarian cancer trials.

\section{Conflicts of Interest}

The Authors report no conflicts of interest.

\section{Authors' Contributions}

CVM was involved in clinical work and contributed with data collection, study design, data analyses, and manuscript writing. KDS was involved in clinical work and contributed with data collection, study design, and manuscript writing. AJ contributed with study design, and manuscript writing. PA was involved in the clinical work and data collection. All authors have read and approved the manuscript.

\section{Acknowledgements}

The Authors would like to thank the trial coordinator Jette Leonhardt Hansen for her assistance with data collection. Furthermore we would like to thank Karin Larsen for linguistic editing of the manuscript.

\section{References}

1 Bookman MA: Update of randomized trials in first-line treatment. Ann Oncol 22: 52-60, 2011. PMID: 22180402. DOI: 10.1093/annonc/mdr466

2 Vasey PA, Jayson GC, Gordon A, Gabra H, Coleman R, Atkinson R, Parkin D, Paul J, Hay A and Kaye SB: Phase III randomized trial of docetaxel-carboplatin versus paclitaxelcarboplatin as first-line chemotherpy for ovarian carcinoma. J Natl Cancer Inst 96: 1682-1691, 2004. PMID: 15547181. DOI: 10.1093/jnci/djh323

3 Katsumata N, Yasuda M, Takahashi F, Isonishi S, Jobo T, Aoki D, Tsuda H, Sugiyama T, Kodama S, Kimura E, Ochiai K and Noda K: Dose-dense paclitaxel once a week in combination with carboplatin every 3 weeks for advanced ovarian cancer: a phase 3, open-label, randomised controlled trial. Lancet 374: 13311338, 2009. PMID: 19767092. DOI: 10.1016/S01406736(09)61157-0

4 Pignata S, Scambia G, Katsaros D, Gallo C, Pujade-Lauraine E, De Placido S, Bologna A, Weber B, Raspagliesi F, Panici PB, Cormio G, Sorio R, Cavazzini MG, Ferrandina G, Breda E, Murgia V, Sacco C, Cinieri S, Salutari V, Ricci C, Pisano C, Greggi S, Lauria R, Lorusso D, Marchetti C, Selvaggi L, Signoriello S, Piccirillo MC, Di Maio M and Perrone F: Carboplatin plus paclitaxel once a week versus every 3 weeks in patients with advanced ovarian cancer (MITO-7): A randomised, multicentre, open-label, phase 3 trial. Lancet Oncol 15: 396-405, 2014. PMID: 24582486. DOI: 10.1016/S1470-2045(14)70049-X

5 Chan JK, Brady MF, Penson RT, Huang H, Birrer MJ, Walker JL, DiSilvestro PA, Rubin SC, Martin LP, Davidson SA, Huh WK, O'Malley DM, Boente MP, Michael $\mathrm{H}$ and Monk BJ: Weekly $v s$. every-3-week paclitaxel and carboplatin for ovarian cancer. N Engl J Med 374: 738-748, 2016. PMID: 26933849. DOI: $10.1056 /$ NEJMoa1505067

6 The ICON and AGO Collaborators: Paclitaxel plus platinumbased chemotherapy versus conventional platinum-based chemotherapy in women with relapsed ovarian cancer: The ICON4/AGO-OVAR-2.2 trial. Lancet 361: 2099-2106, 2003. PMID: 12826431. DOI: 10.1016/S0140-6736(03)13718-X

7 Pujade-Lauraine E, Wagner U, Aavall-Lundqvist E, Gebski V, Heywood M, Vasey PA, Volgger B, Vergote I, Pignata S, Ferrero A, Sehouli J, Lortholary A, Kristensen G, Jackisch C, Joly F, Brown C, Le Fur N and Du Bois A: Pegylated liposomal doxorubicin and carboplatin compared with paclitaxel and carboplatin for patients with platinum-sensitive ovarian cancer in late relapse. J Clin Oncol 28: 3323-3329, 2010. DOI: 10.1200/JCO.2009.25.7519

8 Mahner S, Meier W, du Bois A, Brown C, Lorusso D, Dell'Anna T, Cretin J, Havsteen H, Bessette P, Zeimet AG, Vergote I, Vasey P, Pujade-Lauraine E, Gladieff L and Ferrero A: Carboplatin and pegylated liposomal doxorubicin versus carboplatin and paclitaxel in very platinum-sensitive ovarian cancer patients: results from a subset analysis of the CALYPSO phase III trial. Eur J Cancer 51: 352-358, 2015. PMID: 25534295. DOI: 10.1016/j.ejca.2014.11.017

9 Le T, Hopkins L, Baines KA, Rambout L, Al Hayki M and Kee Fung MF: Prospective evaluations of continuous weekly paclitaxel regimen in recurrent platinum-resistant epithelial ovarian cancer. Gynecol Oncol 102: 49-53, 2006. PMID: 16375951. DOI: $10.1016 /$ j.ygyno.2005.11.025 
10 ten Bokkel Huinink W, Lane SR and Ross GA: Long-term survival in a phase III, randomised study of topotecan versus paclitaxel in advanced epithelial ovarian carcinoma. Ann Oncol 15: 100-103, 2004. DOI: 10.1093/annonc/mdh025

11 Rosenberg P, Andersson H, Boman K, Ridderheim M, Sorbe B, Puistola U and Parö G: Randomized trial of single agent paclitaxel given weekly versus every three weeks and with peroral versus intravenous steroid premedication to patients with ovarian cancer previously treated with platinum. Acta Oncol 41: 418-24, 2002. PMID: 12442916. DOI: 10.1080/028418602320404998

12 Luvero D, Milani A and Ledermann JA: Treatment options in recurrent ovarian cancer: latest evidence and clinical potential. Ther Adv Med Oncol 6: 229-239, 2014. PMID: 25342990. DOI: $10.1177 / 1758834014544121$

13 Armstrong DK: Relapsed Ovarian Cancer: Challenges and Management Strategies for a Chronic Disease. Oncologist 7: 2028,2002. DOI: 10.1634/theoncologist.7-suppl_5-20

14 Corrado G, Salutari V, Palluzzi E, Distefano MG, Scambia G and Ferrandina G: Optimizing treatment in recurrent epithelial ovarian cancer. Expert Rev Anticancer Ther 17: 1147-1158, 2017. PMID: 29086618. DOI: 10.1080/14737140.2017.1398088

15 De Bono JS, Oudard S, Ozguroglu M, Hansen S, MacHiels JP, Kocak I, Gravis G, Bodrogi I, MacKenzie MJ, Shen L, Roessner M, Gupta S and Sartor AO: Prednisone plus cabazitaxel or mitoxantrone for metastatic castration-resistant prostate cancer progressing after docetaxel treatment: A randomised open-label trial. Lancet 376: 1147-1154, 2010. PMID: 20888992. DOI: 10.1016/S0140-6736(10)61389-X

16 Pivot X, Koralewski P, Hidalgo JL, Chan A, Gonçalves A, Schwartsmann G, Assadourian S and Lotz JP: A multicenter phase II study of XRP6258 administered as a 1-h i.v. infusion every 3 weeks in taxane-resistant metastatic breast cancer patients. Ann Oncol 19: 1547-1552, 2008. PMID: 18436520. DOI: $10.1093 /$ annonc/mdn171

17 Sanofi-Aventis Canada Inc.: Jevtana (cabazitaxel) Product Monograph. 1-50, 2017. Available at: http://products.sanofi.ca/en/ jevtana.pdf [Last accessed on $1^{\text {st }}$ September 2019]

18 Rustin GJS, Vergote I, Eisenhauer E, Pujade-Lauraine E, Quinn M, Thigpen T, du Bois A, Kristensen G, Jakobsen A, Sagae S, Greven K, Parmar M, Friedlander M, Cervantes A, Vermorken $\mathrm{J}$ and Gynecological Cancer Intergroup: Definitions for response and progression in ovarian cancer clinical trials incorporating RECIST 1.1 and CA 125 agreed by the Gynecological Cancer Intergroup (GCIG). Int J Gynecol Cancer 21: 419-423, 2011. PMID: 21270624. DOI: 10.1097/IGC.0b013e3182070f17

19 Aaronson NK, Ahmedzai S, Bergman B, Bullinger M, Cull A, Duez NJ, Filiberti A, Flechtner H, Fleishman SB, Haes JCJMD, Kaasa S, Klee M, Osoba D, Razavi D, Rofe PB, Schraub S, Sneeuw K, Sullivan M and Takeda F: The European organization for research and treatment of cancer QLQ-C30: A quality-of-life instrument for use in international clinical trials in oncology. $\mathrm{J}$ Natl Cancer Inst 85: 365-376, 1993. PMID: 8433390. DOI: 10.1093/jnci/85.5.365

20 Fayers PM, Aaronson NK, Bjordal K, Groenvold M, Curran D, Bottomley A, on behalf of the EORTC Quality of Life Group. The EORTC QLQ-C30 Scoring Manual (3rd Edition). Brussels, European Organisation for Research and Treatment of Cancer, 2001.
21 Kotsakis A, Matikas A, Koinis F, Kentepozidis N, Varthalitis II, Karavassilis V, Samantas E, Katsaounis P, Dermitzaki EK, Hatzidaki D, Mavroudis D and Georgoulias V: A multicentre phase II trial of cabazitaxel in patients with advanced non-smallcell lung cancer progressing after docetaxel-based chemotherapy. Br J Cancer 115: 784-788, 2016. PMID: 27607471. DOI: 10.1038/bjc.2016.281

22 Schmalenberg H, Al-Batran S-E, Pauligk C, Zander T, Reichart A, Lindig U, Kleiß M, Müller L, Bolling C, Seufferlein T, Reichardt P, Kullmann F, Eschenburg H, Schmittel A, Egger M, Block A and Goetze TO: CabaGast: multicentre, Phase II study with cabazitaxel in previously treated patients with advanced or metastatic adenocarcinoma of the esophagogastric junction and stomach. J Cancer Res Clin Oncol 144: 559-569, 2018. PMID: 29285668. DOI: $10.1007 / \mathrm{s} 00432-017-2565-5$

23 Pujade-Lauraine E, Hilpert F, Weber B, Reuss A, Poveda A, Kristensen G, Sorio R, Vergote I, Witteveen P, Bamias A, Pereira D, Wimberger P, Oaknin A, Mirza MR, Follana P, Bollag D and Ray-Coquard I: Bevacizumab combined with chemotherapy for platinum-resistant recurrent ovarian cancer: The AURELIA open-label randomized phase III trial. J Clin Oncol 32: 13021308, 2014. PMID: 24637997. DOI: 10.1200/JCO.2013.51.4489

24 Poveda AM, Selle F, Hilpert F, Reuss A, Savarese A, Vergote I, Witteveen P, Bamias A, Scotto N, Mitchell L and Pujade-Lauraine E: Bevacizumab combined with weekly paclitaxel, pegylated liposomal doxorubicin, or topotecan in platinum-resistant recurrent ovarian cancer: Analysis by chemotherapy cohort of the randomized phase III aurelia trial. J Clin Oncol 33: 3836-3838, 2015. PMID: 26282651. DOI: 10.1200/JCO.2015.63.1408

25 Sanofi Genzyme: Jevtana, Summary of product characteristics. Available at: https://www.medicines.org.uk/emc/product/4541/smpc [Last accessed on 18 th October 2019]

26 Ezendam NPM, Pijlman B, Bhugwandass C, Pruijt JFM, Mols F, Vos MC, Pijnenborg JMA and Van De Poll-Franse LV: Chemotherapy-induced peripheral neuropathy and its impact on health-related quality of life among ovarian cancer survivors: Results from the population-based PROFILES registry. Gynecol Oncol 135: 510-517, 2014. PMID: 25281491. DOI: 10.1016/j.ygyno.2014.09.016

27 Brewer JR, Morrison G, Dolan ME and Fleming GF: Chemotherapy-induced peripheral neuropathy: Current status and progress. Gynecol Oncol 140(1): 176-183, 2015. PMID: 26556766. DOI: 10.1016/j.ygyno.2015.11.011

28 Ewertz M, Qvortrup C and Eckhoff L: Chemotherapy-induced peripheral neuropathy in patients treated with taxanes and platinum derivatives. Acta Oncol 54(5): 587-591, 2015. PMID: 25751757. DOI: 10.3109/0284186X.2014.995775

Received April 19, 2020

Revised July 27, 2020

Accepted July 28, 2020 